\title{
Ahmad Azadi, Enrico Ascalone, Luca Peyronel. The First Season (2009) of Archaeological Research by the Iranian-Italian Joint Expedition at Qaleh Kutchek, Halil Valley (Jiroft, Kerman Province, SE Iran)
}

Rémy Boucharlat

\section{(2) OpenEdition}

\section{Journals}

Édition électronique

URL : http://journals.openedition.org/abstractairanica/41643

DOI : $10.4000 /$ abstractairanica. 41643

ISSN : 1961-960X

Éditeur :

CNRS (UMR 7528 Mondes iraniens et indiens), Éditions de l'IFRI

Référence électronique

Rémy Boucharlat, « Ahmad Azadi, Enrico Ascalone, Luca Peyronel. The First Season (2009) of Archaeological Research by the Iranian-Italian Joint Expedition at Qaleh Kutchek, Halil Valley (Jiroft, Kerman Province, SE Iran) », Abstracta Iranica [En ligne], Volume 34-35-36 | 2017, document 66, mis en ligne le 15 juillet 2016, consulté le 28 septembre 2020. URL : http://journals.openedition.org/abstractairanica/ 41643 ; DOI : https://doi.org/10.4000/abstractairanica.41643

Ce document a été généré automatiquement le 28 septembre 2020.

Tous droits réservés 
Ahmad Azadi, Enrico Ascalone, Luca Peyronel. The First Season (2009) of Archaeological Research by the IranianItalian Joint Expedition at Qaleh Kutchek, Halil Valley (Jiroft, Kerman Province, SE Iran)

Rémy Boucharlat 


\section{RÉFÉRENCE}

Ahmad Azadi, Enrico Ascalone, Luca Peyronel. « The First Season (2009) of Archaeological Research by the Iranian-Italian Joint Expedition at Qaleh Kutchek, Halil Valley (Jiroft, Kerman Province, SE Iran) », in : Roger Matthews, John Curtis, eds., Proceedings of the 7th International Congress on the Archaeology of the Ancient Near East (ICAANE), 12 April - 16 April 2010, The British Museum and UCL, London, vol. 3 Fieldwork \& Recent Research. Wiesbaden, Harrassowitz, p. 277-302.

Dans la vallée du Halīl Rūd devenue célèbre grâce aux étonnantes découvertes dites de Jīroft (nécropoles - pillée - et énormes constructions du $3^{\mathrm{e}}$ mill.), la mission iranoitalienne a prospecté la partie amont de la vallée. On retiendra que le site le plus vaste, $75 \mathrm{ha}$, à $18 \mathrm{~km}$ au sud-ouest de Jïroft, a connu une occupation à l'âge du Bronze (nécropole), mais plus importante à l'âge du Fer II (800-600 av. J.-C.) et à l'époque achéménide, ainsi que dans les siècles suivants. Ces périodes sont très mal connues dans le sud-est de l'Iran ce qui donne toute son importance au site prometteur de Qal'e Kūček.

\section{AUTEURS}

\section{RÉMY BOUCHARLAT}

CNRS, Lyon 